\title{
Carbonic anhydrase inhibitors in patients with respiratory failure and metabolic alkalosis: a systematic review and meta- analysis of randomized controlled trials
}

Bassem Y Tanios ${ }^{1}$, Maryam O Omran², Carlos Noujeim ${ }^{3}$, Tamara Lotfi ${ }^{4}$, Samir S Mallat ${ }^{1,8^{*}}$, Pierre K Bou-Khalii ${ }^{5,8^{*}}$, Elie A Akl ${ }^{6}$ and Houssam S Itani ${ }^{7}$

\begin{abstract}
Background: Metabolic alkalosis is common in patients with respiratory failure and may delay weaning in mechanically ventilated patients. Carbonic anhydrase inhibitors block renal bicarbonate reabsorption, and thus reverse metabolic alkalosis. The objective of this systematic review is to assess the benefits and harms of carbonic anhydrase inhibitor therapy in patients with respiratory failure and metabolic alkalosis.

Methods: We searched the following electronic sources from inception to August 2017: the Cochrane Central Register of Controlled Trials (CENTRAL), MEDLINE, EMBASE, and SCOPUS. Randomized clinical trials were included if they assessed at least one of the following outcomes: mortality, duration of hospital stay, duration of mechanical ventilation, adverse events, and blood gas parameters. Teams of two review authors worked in an independent and duplicate manner to select eligible trials, extract data, and assess risk of bias of the included trials. We used meta-analysis to synthesize statistical data and then assessed the certainty of evidence using the GRADE methodology.

Results: Six eligible studies were identified with a total of 564 participants. The synthesized data did not exclude a reduction or an increase in mortality (risk ratio (RR) $0.94,95 \%$ confidence interval (CI) 0.57 to 1.56 ) or in duration of hospital stay (mean difference (MD) 0.42 days, $95 \% \mathrm{Cl}-4.82$ to 5.66) with the use of carbonic anhydrase inhibitors. Carbonic anhydrase inhibitor therapy resulted in a decrease in the duration of mechanical ventilation of $27 \mathrm{~h}(95 \% \mathrm{Cl}$ -50 to -4$)$. Also, it resulted in an increase in $\mathrm{PaO}_{2}\left(\mathrm{MD} 11.37 \mathrm{mmHg}, 95 \% \mathrm{Cl} 4.18\right.$ to 18.56) and a decrease in $\mathrm{PaCO}_{2}$ ( $\mathrm{MD}-4.98 \mathrm{mmHg}, 95 \% \mathrm{Cl}-9.66,-0.3$ ), serum bicarbonate ( $\mathrm{MD}-5.03 \mathrm{meq} / \mathrm{L}, 95 \% \mathrm{Cl}-6.52$ to -3.54$)$, and $\mathrm{pH}$ ( $\mathrm{MD}-0$. $04,95 \% \mathrm{Cl}-0.07$ to -0.01 ). There was an increased risk of adverse events in the carbonic anhydrase inhibitor group (RR $1.71,95 \% \mathrm{Cl} 0.98$ to 2.99). Certainty of evidence was judged to be low for most outcomes.

Conclusion: In patients with respiratory failure and metabolic alkalosis, carbonic anhydrase inhibitor therapy may have favorable effects on blood gas parameters. In mechanically ventilated patients, carbonic anhydrase inhibitor therapy may decrease the duration of mechanical ventilation. A major limitation of this finding was that only two trials assessed this clinically important outcome.
\end{abstract}

Keywords: Carbonic anhydrase inhibitors, Respiratory failure, Metabolic alkalosis, Mechanical ventilation, Systematic review

\footnotetext{
*Correspondence: sm104@aub.edu.lb; pb05@aub.edu.lb

'Division of Nephrology and Hypertension, American University of Beirut

Medical Center, Beirut, Lebanon

${ }^{5}$ Division of Pulmonary and Critical Care, American University of Beirut

Medical Center, Beirut, Lebanon

Full list of author information is available at the end of the article
}

(c) The Author(s). 2018 Open Access This article is distributed under the terms of the Creative Commons Attribution 4.0 International License (http://creativecommons.org/licenses/by/4.0/), which permits unrestricted use, distribution, and reproduction in any medium, provided you give appropriate credit to the original author(s) and the source, provide a link to the Creative Commons license, and indicate if changes were made. The Creative Commons Public Domain Dedication waiver (http://creativecommons.org/publicdomain/zero/1.0/) applies to the data made available in this article, unless otherwise stated. 


\section{Background}

Metabolic alkalosis is common in patients with respiratory failure $[1,2]$. There is evidence that increased $\mathrm{pH}$ level in the cerebrospinal fluid may depress respiratory drive and may delay weaning in patients with respiratory failure on mechanical ventilation $[3,4]$.

Carbonic anhydrase inhibitors (CAI) (such as acetazolamide, methazolamide, and dichlorphenamide) block renal bicarbonate reabsorption, and thus reverse metabolic alkalosis [3]. However, uncertainty remains about their effects in the setting of respiratory failure with concurrent metabolic alkalosis on duration of hospitalization, mechanical ventilation (MV), or noninvasive positivepressure ventilation (NIPPV), and mortality [3].

A Cochrane systematic review on the use of CAI for hypercapnic ventilatory failure in chronic obstructive pulmonary disease (COPD) identified four eligible trials. The review found that acetazolamide therapy resulted in a significant improvement in $\mathrm{PO}_{2}$ and a nonsignificant decrease in $\mathrm{PaCO}_{2}$. However, the included studies had a limited number of participants (84 patients), had short-term follow-ups, did not assess clinically important outcomes such as duration of hospitalization and mortality, and none included patients on NIPPV or MV [5].

Since the publication of the Cochrane review in 2001, several trials have been published [6-8]. In a multicenter randomized controlled trial (RCT), acetazolamide therapy in 382 patients with COPD and metabolic alkalosis on mechanical ventilation resulted in a 16-h decrease in the duration of mechanical ventilation compared with placebo (95\% confidence interval (CI) -36.5 to $4.0 \mathrm{~h} ; p=0.17$ ) [6]. A smaller trial with 22 patients with COPD with respiratory failure, metabolic alkalosis, and on NIPPV, found that acetazolamide therapy significantly reduced the duration of NIPPV compared with a matched control group $(6 \pm 8$ versus $19 \pm 19$ days; $p=0.03$ ) [7].

Given the current uncertainty about the benefits and harms of using CAI in patients with respiratory failure and metabolic alkalosis, it would be informative for clinical practice to synthesize and critically appraise the current body of evidence.

\section{Objective}

The objective of this systematic review was to assess the benefits and harms of carbonic CAI therapy in patients with respiratory failure and metabolic alkalosis.

\section{Methods}

The detailed methods are included in Additional file 1.

\section{Eligibility criteria}

RCTs were included if they recruited patients with respiratory failure and concurrent metabolic alkalosis (as defined by the individual trial), including patients on
MV or NIPPV. In addition, the trial should have compared CAI to either placebo or usual care. All co-interventions should have been similar for the two comparison groups.

The primary outcomes of interest were duration of hospital stay, duration of MV or NIPPV, mortality, and adverse events. Secondary outcomes included the blood gases parameters $\mathrm{PaCO}_{2}, \mathrm{PO}_{2}, \mathrm{HCO}_{3}$, and $\mathrm{PH}$.

\section{Search strategy}

We searched the following electronic databases from inception to August 2017: the Cochrane Central Register of Controlled Trials (CENTRAL), MEDLINE, EMBASE, and SCOPUS. Figures 1 to 4 in Additional file 2 detail the electronic search strategy. There were no language or date restrictions. We also screened the reference lists of included trials and identified related systematic reviews. The search strategy did not include attempts at collecting unpublished data.

\section{Selection process}

Teams of two review authors (BYT and CN, and HSI and MOO) screened independently and in duplicate the abstract and title of every record captured by the searches. We retrieved the full texts for all citations judged as potentially eligible by at least one reviewer.

The teams of two reviewers then assessed the full texts for eligibility using a standardized screening form.

A PRISMA (preferred reporting items for systematic reviews and meta-analyses) flow-chart was used to summarize the results of the selection process [9] (Fig. 1).

\section{Data extraction}

We extracted information about the study design, the clinical characteristics of the trial (population, intervention, comparator, and outcomes), funding, and conflicts of interest of the authors.

\section{Assessment of risk of bias}

Risk of bias was assessed using The Cochrane Collaboration's Risk of Bias tool [10, 11]. The following criteria were used: random sequence generation (selection bias), allocation concealment (selection bias), blinding of participants, providers, data collectors, outcome adjudicators, and data analysts (performance bias and detection bias), incomplete outcome data (attrition bias), selective outcome reporting (reporting bias), and other biases (including early stopping for benefit).

Risk of bias criteria was judged as 'low risk', 'high risk' or 'unclear risk' as described in the Cochrane Handbook for Systematic Reviews of Interventions [10]. 


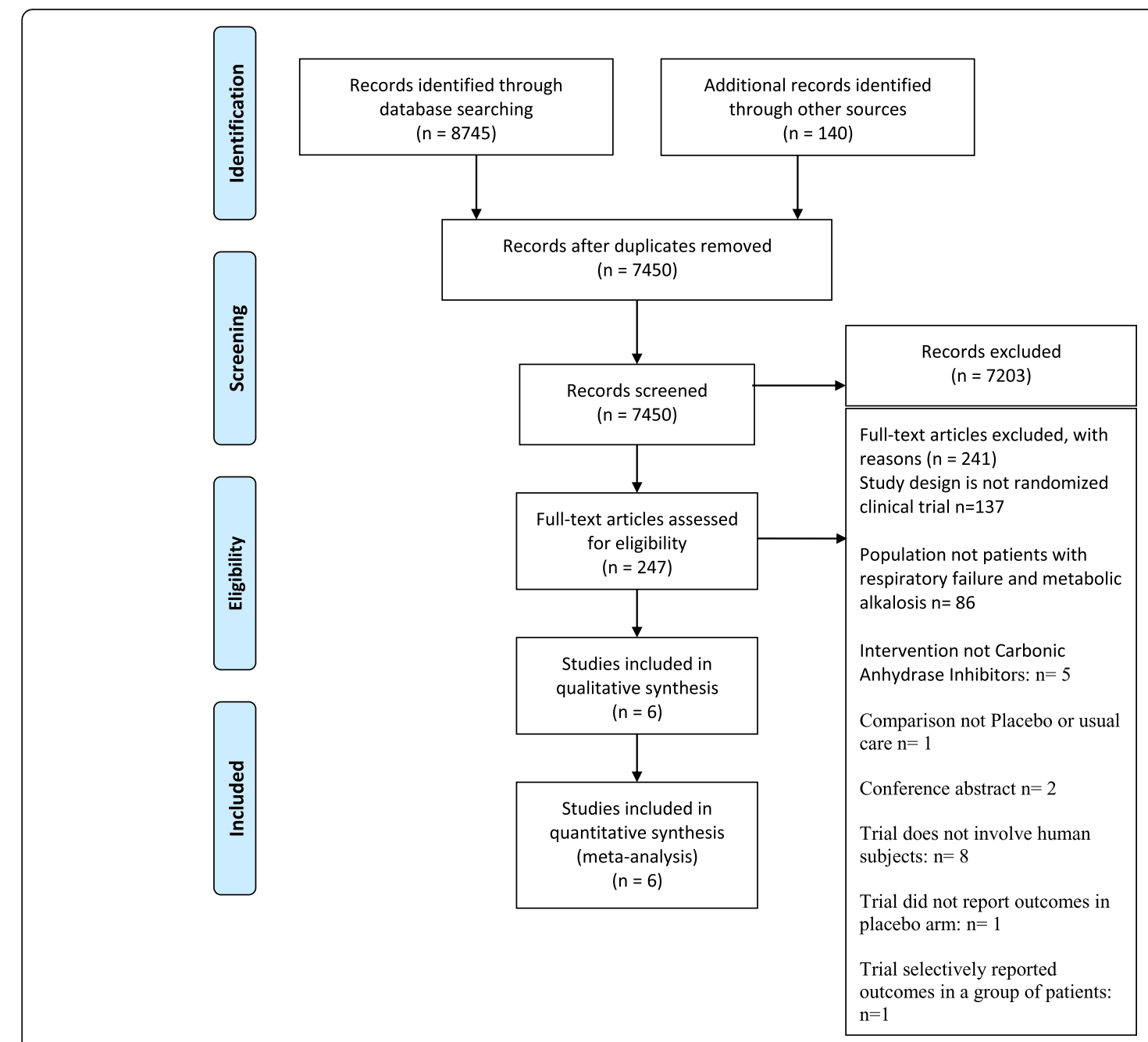

Fig. 1 PRISMA study flowchart

\section{Data analysis}

For dichotomous data, we used the risk ratio (RR) with 95\% CIs. For continuous outcomes data, we used, whenever possible, the mean change score from baseline to follow-up for each intervention group.

One of the of the included trials (Nelson and Wallace, 1965 [12]) did not report standard deviations (SDs) in the assessment of the outcomes for $\mathrm{PaCO}_{2}$ and serum bicarbonate. Therefore, we used the median SD from the other included trials that reported SDs for these outcomes, as described in Furukawa et al. [13]. In another trial (Faisy et al., 2016 [14]), the authors did not report means and SDs and so these were extrapolated respectively from the reported medians $($ mean $=$ median $)$ and interquartile range (IQR) (SD = IQR/1.35) [10]. In Hacki et al., 1983 [15], outcomes data were extracted from a graph in the report using the WebPlotDigitizer tool [16].

We pooled data using the random-effects model for the primary meta-analyses [17]. Heterogeneity (inconsistency) between study results was assessed using the $I^{2}$ statistic. An $I^{2}$ value of $50 \%$ or more was indicative of a considerable level of heterogeneity [10]. To explain any heterogeneity, we planned to conduct subgroup analyses based on the following variables: specific type and dose of CAI, etiology of respiratory failure, spontaneously breathing patients or on MV or NIPPV, and severity of metabolic alkalosis.

We also planned to perform sensitivity analyses to explore the influence of the following factors (when applicable) on pooled effect sizes: restricting the analyses to studies with low risk of bias, restricting the analyses to studies with longer follow-up, and assessing the impact of missing data. [18-21].

\section{Assessment of certainty of the evidence}

Certainty of the evidence for each outcome was assessed using the Grading of Recommendations Assessment, Development and Evaluation (GRADE) approach [22]. This approach classifies the certainty of evidence into 
four categories: high, moderate, low, and very low. It takes into account the following factors: risk of bias [23], imprecision, inconsistency [24], indirectness [25], and publication bias [26]. We developed a Summary of Findings (SoF) table using the GRADEpro/GDT tool [27].

\section{Results}

\section{Search results}

Figure 1 shows the study flow chart. Out of 7450 screened citations, six eligible studies were identified with a total of 578 participants.

\section{Included studies}

Table 1 summarizes the characteristics of the included studies. Five trials were in the English language, and one trial was in German. All studies were randomized. Four trials used a parallel group design $[6,8,28,29]$, one trial used a cross-over design [12], and one trial [15] used a cross-over design during the short-term intervention and a parallel design during long-term intervention.

Only two trials (Faisy et al. and Rialp Cervera et al.) included patients on mechanical ventilation $[6,8]$, while the other four trials included outpatients and inpatients not on mechanical ventilation. Four trials included COPD patients exclusively [12, 28-30]. In the study by Rialp Cervera et al., 90\% of participants had COPD while $10 \%$ had obesity hypoventilation syndrome [8]. Faisy et al. included patients on mechanical ventilation secondary mostly to community-acquired pneumonia and bronchitis [6]. Five trials evaluated acetazolamide, while one trial (Nelson and Wallace) evaluated dichlorphenamide [12]. Additional file 2 (Table S5) details the funding and conflicts of interest of authors in the included trials.

\section{Risk of bias in included trials}

Additional file 2 (Figure S1) and Table 2 summarize the risk of bias assessment in the included trials. Most of the included trials were judged to have a low risk of bias for most of the criteria. An unclear risk of bias was judged for some trials $[6,12,29,30]$, especially when methods of random sequence generation and allocation concealment were not specified. A high-risk attrition bias was judged for Nelson and Wallace because 12 patients were included in the final analysis out of the initial 19 patients included in the trial [12]. A high "other risk of bias" was also judged for Faisy et al. [6], taking into consideration that we extrapolated means and SDs as described above.

\section{Effects of the intervention}

\section{Mortality}

The analysis based on the two trials that reported mortality did not exclude a reduction or an increase in mortality (RR $0.94,95 \%$ CI 0.57 to $1.56 ; I^{2}=0 \%$ ). Certainty of evidence was judged to be low due to very serious imprecision (Additional file 2: Figure S2; see the SoF in Table 3).

\section{Duration of hospital stay}

Only two trials assessed the duration of hospital stay, and the pooled analysis did not exclude a reduction or an increase in duration of hospital stay (mean difference (MD) 0.42 days, $95 \% \mathrm{CI}-4.82$ to $5.66 ; I^{2}=33 \%$ ) (Additional file 2: Figure S3). Certainty of evidence was judged to be low due to very serious imprecision (Table 3 ).

\section{Duration of MV or NIPPV}

Pooled data from the two trials that included patients on MV found that CAI therapy resulted in a 27.09-h mean reduction in duration of $\mathrm{MV}(95 \% \mathrm{CI}-50.11$ to -4.08 ; $I^{2}=0 \%$ ) (Additional file 2: Figure S4). Certainty of evidence was judged to be low due to imprecision and serious risk of bias (Table 3).

\section{$\mathrm{PaCO}_{2}$}

The main analysis included five trials and excluded Faisy et al. [6] because they reported daily mean change in $\mathrm{PaCO}_{2}$. The meta-analysis showed that CAI therapy resulted in a mean reduction of $-4.98 \mathrm{mmHg}$ in $\mathrm{PaCO}_{2}$ (95\% CI -9.66 to $-0.30 ; I^{2}=95 \%$ ) (Fig. 2). The result did not change substantially after including Faisy et al. using the standardized mean difference (SMD) (Additional file 2: Figure S5).

\section{$\mathrm{PaO}_{2}$}

The main analysis included three trials and excluded Faisy et al. and Rialp Cervera et al. who reported $\mathrm{Pa} / \mathrm{FiO}_{2}$, and Nelson and Wallace who did not report on this outcome. The meta-analysis showed that CAI therapy resulted in a mean increase of $11.37 \mathrm{mmHg}$ in $\mathrm{PaO}_{2}$ (95\% CI 4.18 to 18.56; $I^{2}=98 \%$ ) (Fig. 3). The results still favored the CAI group when we included Faisy et al. and Rialp Cervera et al. using SMD (Additional file 2: Figure S6).

\section{Serum bicarbonate}

The main analysis included two trials and showed a mean reduction of $5 \mathrm{meq} / \mathrm{L}$ in serum bicarbonate in the CAI group (95\% CI -6.52 to $-3.54 ; I^{2}=0 \%$ ) (Fig. 4). Using $\mathrm{SMD}$, we pooled data from trials that reported base excess as a surrogate for serum bicarbonate, and the result showed a reduction in SMD of $-3.98 \mathrm{meq} / \mathrm{L}(95 \% \mathrm{CI}$ -5.47 to $-2.49 ; I^{2}=94 \%$ ) (Additional file 2: Figure S7).

\section{pH}

The main analysis excluded Faisy et al. because they reported the daily mean change in $\mathrm{pH}$. The results showed a mean reduction in $\mathrm{pH}$ of 0.04 in the CAI group $(95 \%$ CI -0.07 to $-0.01 ; I^{2}=98 \%$ ) (Fig. 5). The result did not 


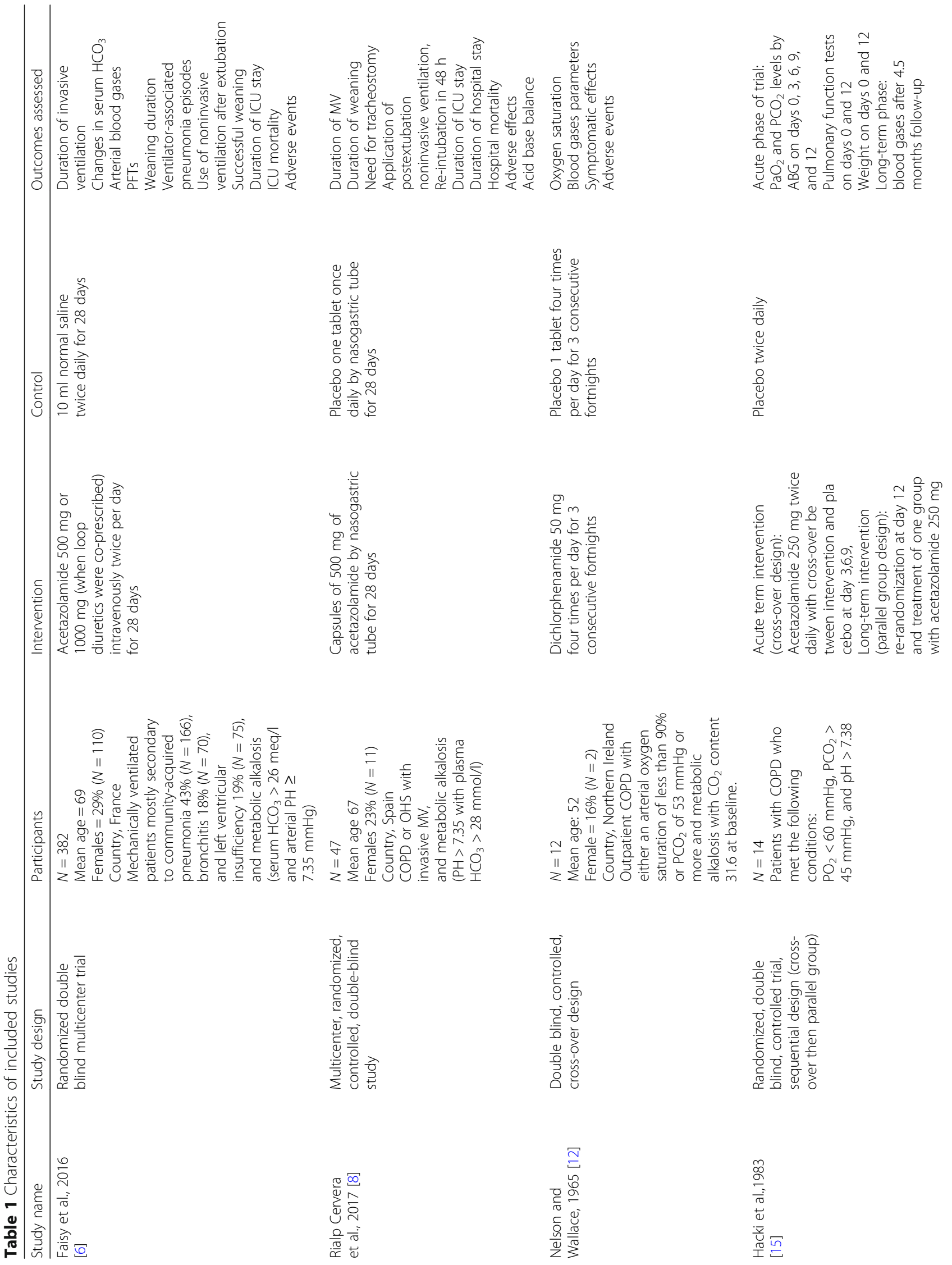




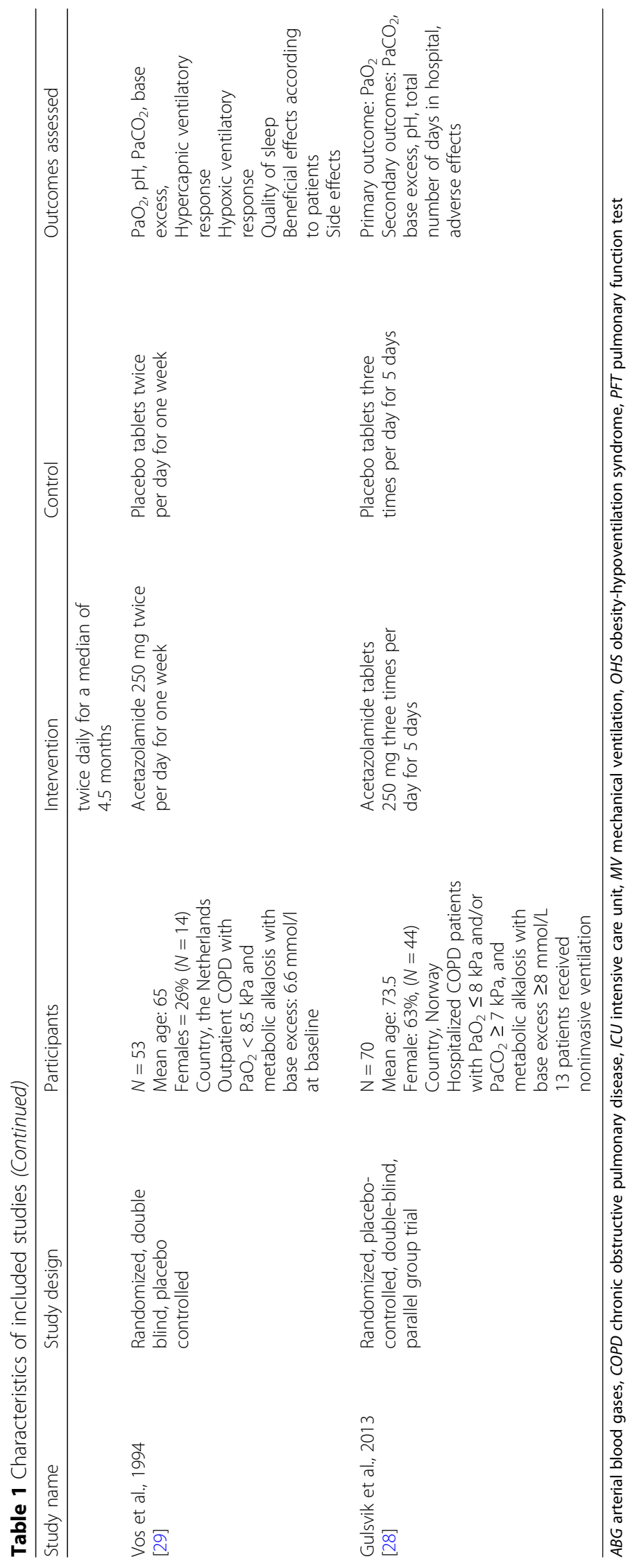




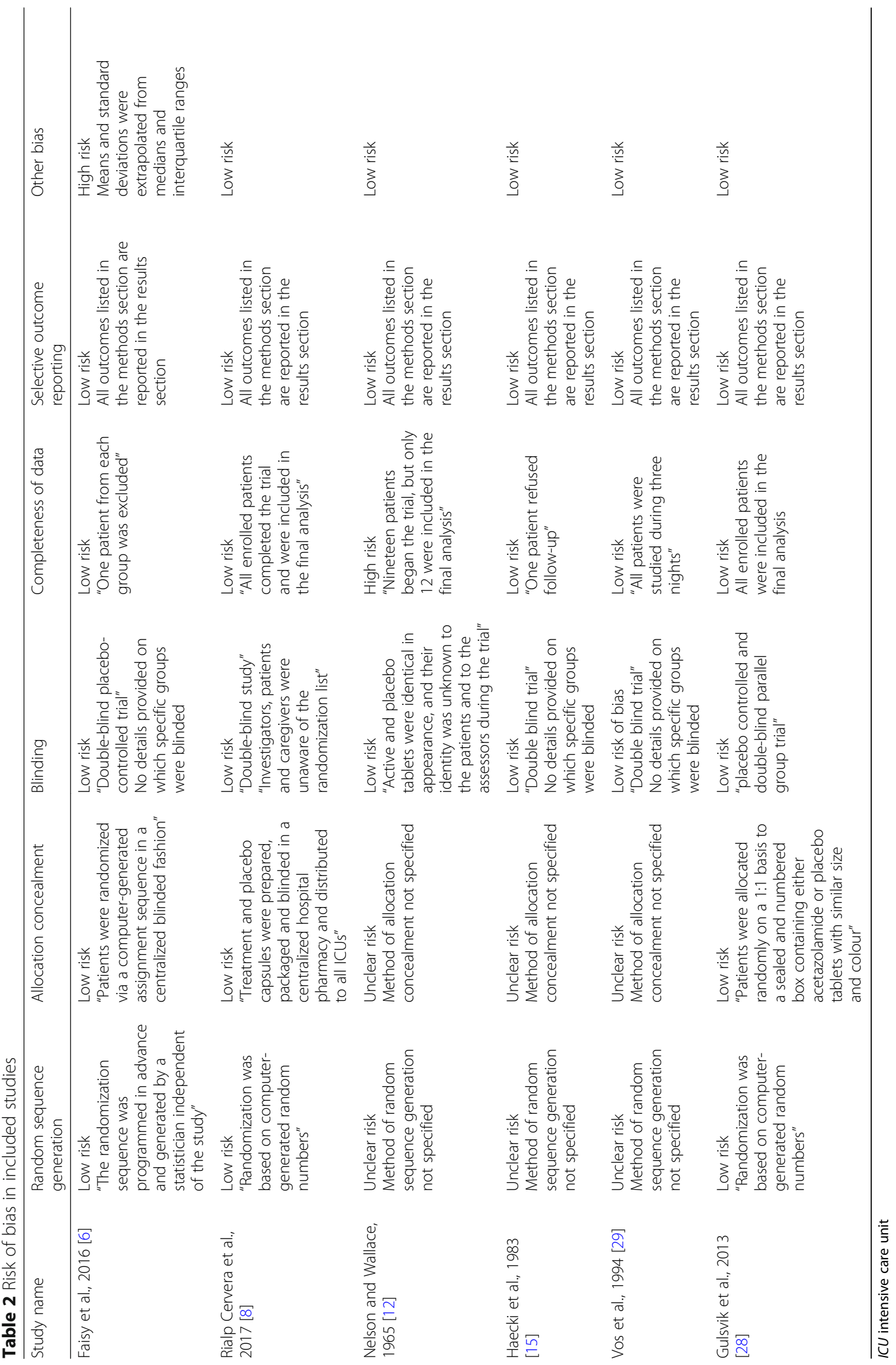


Table 3 Summary of findings

\begin{tabular}{|c|c|c|c|c|c|}
\hline \multirow[t]{2}{*}{ Outcomes } & \multicolumn{2}{|c|}{ Anticipated absolute effects ( $95 \% \mathrm{Cl}$ ) } & \multirow{2}{*}{$\begin{array}{l}\text { Relative effect } \\
(95 \% \mathrm{Cl})\end{array}$} & \multirow{2}{*}{$\begin{array}{l}\text { No. of } \\
\text { participants } \\
\text { (studies) }\end{array}$} & \multirow{2}{*}{$\begin{array}{l}\text { Certainty of the } \\
\text { evidence (GRADE) }\end{array}$} \\
\hline & Risk with control & Risk with carbonic anhydrase & & & \\
\hline $\begin{array}{l}\text { Duration of hospital } \\
\text { stay (days) }\end{array}$ & & $\begin{array}{l}\text { The mean duration of hospital stay in the intervention } \\
\text { group was } 0.42 \text { days more ( } 4.82 \text { fewer to } 5.66 \text { more) }\end{array}$ & - & 117 (2 RCTs) & $\oplus \oplus \circ O \mathrm{LOW}^{\mathrm{a}}$ \\
\hline $\begin{array}{l}\text { Duration of mechanical } \\
\text { ventilation ( } h \text { ) }\end{array}$ & & $\begin{array}{l}\text { The mean duration of mechanical ventilation in the } \\
\text { intervention group was } 27.09 \mathrm{~h} \text { lower ( } 50.11 \text { lower } \\
\text { to } 4.08 \text { lower) }\end{array}$ & - & 427 (2 RCTs) & $\oplus \oplus O O L_{O} W^{b, c}$ \\
\hline Mortality & 130 per 1000 & 122 per 1000 (74 to 202) & $\begin{array}{l}\text { RR } 0.94(0.57 \\
\text { to } 1.56)\end{array}$ & 427 (2 RCTs) & $\oplus \oplus \circ O \mathrm{LOW}^{\mathrm{a}}$ \\
\hline Adverse events & 78 per 1000 & 133 per 1000 (76 to 232) & $\begin{array}{l}\text { RR } 1.71(0.98 \\
\text { to } 2.99)\end{array}$ & 508 (5 RCTs) & $\oplus \oplus \oplus O$ MODERATE \\
\hline
\end{tabular}

Carbonic anhydrase inhibitors were compared with control for respiratory failure with metabolic alkalosis

Patient or population: respiratory failure with metabolic alkalosis

Intervention: carbonic anhydrase inhibitors

Comparison: control

$C l$ confidence interval, $R C T$ randomized controlled trial, $R R$ risk ratio

${ }^{a}$ Wide confidence intervals, very serious imprecision

${ }^{b}$ Wide confidence intervals, serious imprecision

${ }^{c}$ We extrapolated mean and standard deviation from the median and interquartile ranges reported in the trial

change substantially when Faisy et al. was incorporated using SMD (Additional file 2: Figure S8).

\section{Adverse events}

The analysis from the five trials that reported on adverse outcomes showed an increased risk of adverse events in the CAI group (RR 1.71, 95\% CI 0.98 to $2.99 ; I^{2}=19 \%$ ) (Fig. 6). Certainty of evidence was judged to be moderate due to imprecision (Table 3).

This result was mainly driven by increased incidence of mild side effects such as vertigo, paresthesia, nausea, vomiting, headache, skin rash, and abdominal discomfort in Nelson and Wallace and Vos et al. [12, 29], and increased incidence of hypokalemia and serum bicarbonate
$<23 \mathrm{mmol} / \mathrm{L}$ in the acetazolamide group in Rialp Cervera et al. [8]. In the study of Hacki et al., the authors reported that no side effects or severe metabolic acidosis were noted in the two groups [15].

On the other hand, there was no increased incidence of serious adverse reactions in the CAI group in the study of Faisy et al., as defined by events that required intensive care procedures and/or surgery, and events that prolonged hospitalization or resulted in persistent or major disability/incapacity, and in Rialp Cervera et al. as defined by serum creatinine $>2.5 \mathrm{~g} / \mathrm{dL}$, bilirubin $>$ $3.5 \mathrm{mg} / \mathrm{dL}$, prothrombin activity $<40 \%$, leukocyte count $<4 \times 10^{9} / \mathrm{L}$, platelets $<150 \times 10^{9} / \mathrm{L}$, appearance of seizures, or severe allergic reaction $[6,8]$.

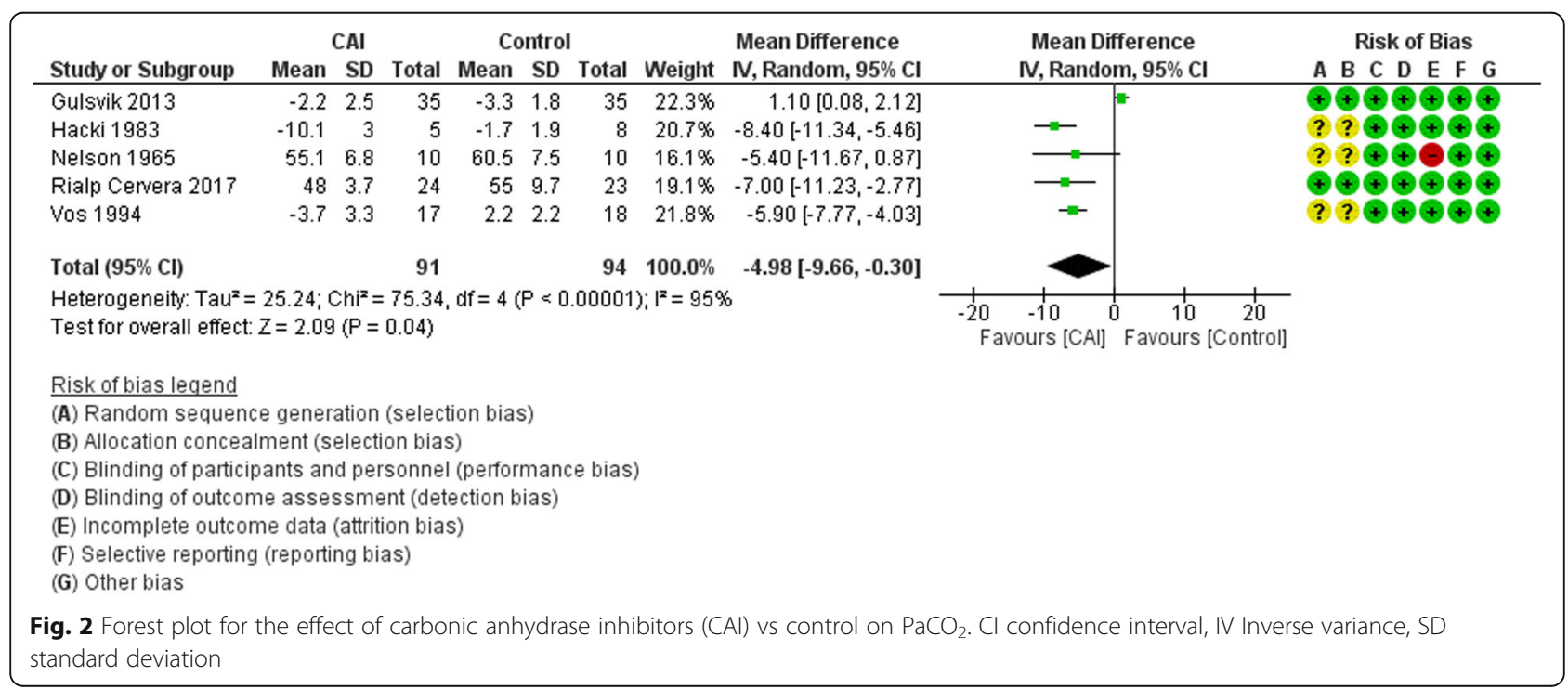




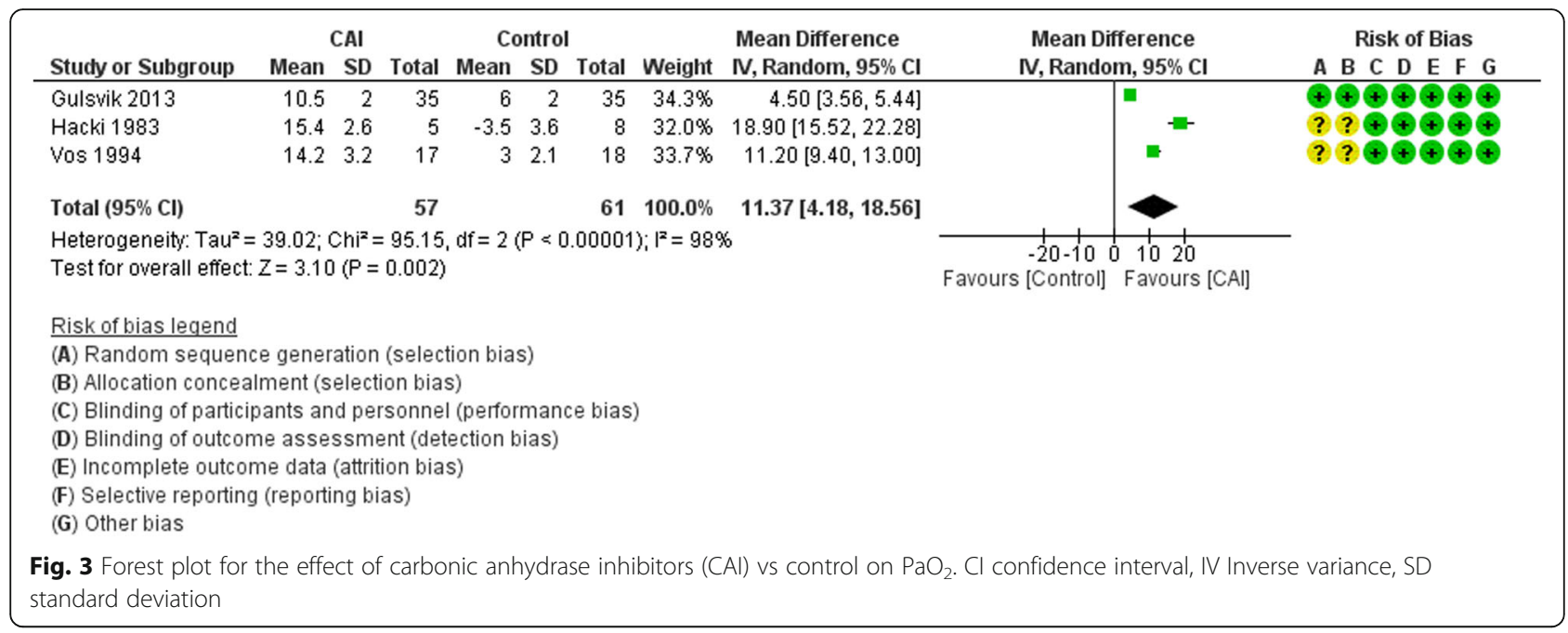

\section{Subgroup and sensitivity analyses}

Pre-planned subgroup and sensitivity analyses were not possible because of the limited number of included trials.

\section{Discussion}

In summary, we did not find definitive results for the effects of CAI therapy on clinically important outcomes such as mortality and duration of hospital stay in patients with respiratory failure and metabolic alkalosis. The results suggest that CAI therapy may decrease the duration of mechanical ventilation. There was a trend towards increased incidence of adverse events in the CAI group; however, most of these adverse events were mild.

On the other hand, the results suggest that CAI therapy has favorable effects on arterial blood gas parameters $\left(\mathrm{PaCO}_{2}, \mathrm{PaO}_{2}\right.$, bicarbonate and $\left.\mathrm{pH}\right)$, with decreased $\mathrm{PaCO}_{2}$, increased $\mathrm{PaO}_{2}$, and, as expected, decreased bicarbonate and $\mathrm{pH}$ levels.
The main strength of the current review is the use of rigorous systematic review methods. Also, inclusion criteria were restricted to well-designed RCTs with an overall low risk of bias.

The limitations of the current systematic review relate to those of the included studies, mainly their limited number. In addition, some of the included studies did not report all the data required to include them in the meta-analyses. For example, Nelson and Wallace did not provide SDs, and Faisy et al. reported medians and IQRs but not means and SDs. Furthermore, most trials used acetazolamide, and most patients had COPD, and thus our results may not be applicable to CAIs other than acetazolamide and in respiratory conditions other than COPD.

A previously published systematic review focusing on patients with COPD and hypercapnic respiratory failure included four trials with 84 participants. That study reported that acetazolamide therapy significantly decreased $\mathrm{pH}$ and serum bicarbonate and significantly

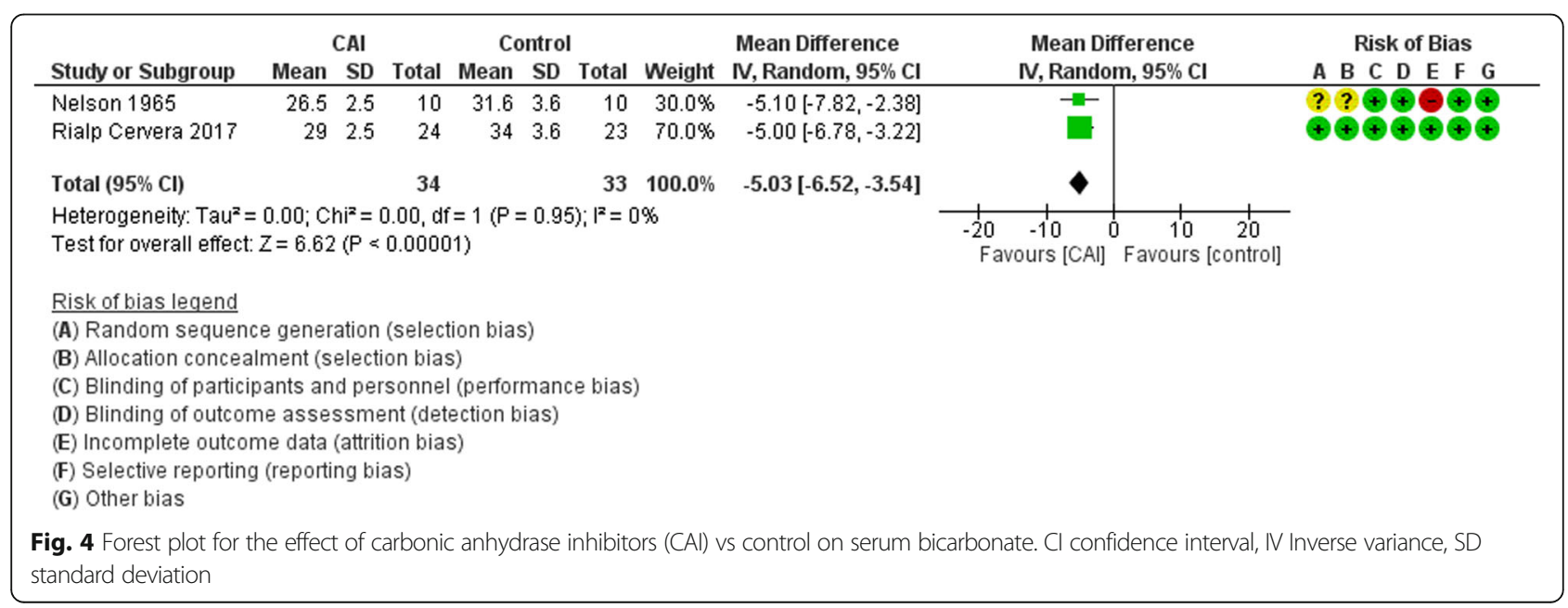




\begin{tabular}{|c|c|c|c|c|c|c|c|c|c|c|}
\hline \multirow[b]{2}{*}{ Study or Subgroup } & \multicolumn{3}{|c|}{ CAI } & \multicolumn{3}{|c|}{ Control } & \multirow[b]{2}{*}{ Weight } & \multirow{2}{*}{$\begin{array}{l}\text { Mean Difference } \\
\text { N, Random, } 95 \% \mathrm{Cl}\end{array}$} & \multirow{2}{*}{$\begin{array}{l}\text { Mean Difference } \\
\text { IV, Random, } 95 \% \mathrm{Cl}\end{array}$} & Risk of Bias \\
\hline & Mean & SD & Total & Mean & SD & Total & & & & A B C D EFG \\
\hline Gulsvik 2013 & -0.09 & 0.01 & 35 & -0.003 & 0.01 & 35 & $26.1 \%$ & $-0.09[-0.09,-0.08]$ & \begin{tabular}{|c|c|c|}
-1 \\
\end{tabular} & $+\oplus+\odot+C+$ \\
\hline Hacki 1983 & -0.05 & 0.02 & 5 & -0.04 & 0.02 & 8 & $23.1 \%$ & $-0.01[-0.03,0.01]$ & $-t$ & 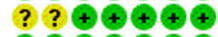 \\
\hline Rialp Cervera 2017 & 7.4 & 0.02 & 24 & 7.41 & 0.03 & 23 & $24.8 \%$ & $-0.01[-0.02,0.00]$ & & $\hookrightarrow \odot \odot \odot \odot \div$ \\
\hline Vos 1994 & -0.07 & 0.01 & 17 & -0.01 & 0.01 & 18 & $26.0 \%$ & $-0.06[-0.07,-0.05]$ & $=$ & ? ? $\odot \odot \oplus \odot \odot$ \\
\hline \multirow{2}{*}{\multicolumn{9}{|c|}{$\begin{array}{l}\text { Total }(\mathbf{9 5} \% \mathrm{Cl}) \\
\text { Heterogeneity: } \mathrm{Tau}^{\mathbf{2}}=0.00 ; \mathrm{Chi}^{\mathbf{2}}=150.43, \mathrm{df}=3(\mathrm{P}<0.00001) ; \mathrm{I}^{\mathbf{2}}=\mathbf{1 0 0 . 0} \%\end{array}$}} & & \\
\hline \multicolumn{7}{|c|}{ Test for overall effect: $Z=2.72(P=0.007)$} & & & $\begin{array}{ccccc}-0.2 & -0.1 & 0 & 0.1 & 0.2 \\
\text { Favours [CAl] } & \text { Favours [control] }\end{array}$ & \\
\hline \multicolumn{11}{|l|}{ Risk of bias legend } \\
\hline \multicolumn{11}{|c|}{ (A) Random sequence generation (selection bias) } \\
\hline \multicolumn{11}{|c|}{ (B) Allocation concealment (selection bias) } \\
\hline \multicolumn{11}{|c|}{ (C) Blinding of participants and personnel (performance bias) } \\
\hline \multicolumn{11}{|c|}{ (D) Blinding of outcome assessment (detection bias) } \\
\hline \multirow{2}{*}{\multicolumn{11}{|c|}{$\begin{array}{l}\text { (E) Incomplete outcome data (attrition bias) } \\
\text { (F) Selective reporting (reporting bias) }\end{array}$}} \\
\hline & & & & & & & & & & \\
\hline \multicolumn{11}{|c|}{$\begin{array}{l}\text { (F) Selective reporting (reporting bias) } \\
\text { (G) Other bias }\end{array}$} \\
\hline \multicolumn{11}{|c|}{$\begin{array}{l}\text { Fig. } 5 \text { Forest plot for the effect of carbonic anhydrase inhibitors (CAl) vs control on pH. Cl confidence interval, IV Inverse variance, SD } \\
\text { standard deviation }\end{array}$} \\
\hline
\end{tabular}

increased $\mathrm{PaO}_{2}$, and led to a small decrease in $\mathrm{PaCO}_{2}$. The study reported those results as not statistically significant [5]. We have excluded two of the trials included in that review (Skatrud and Dempsey [31] and Wagenaar et al. [32]) because they did not meet our eligibility criteria. Skatrud and Dempsey reported outcomes exclusively in patients deemed as "correctors" to acetazolamide, and in Wagenaar et al. the arms comparing acetazolamide with placebo were not randomized [31, 32]. Furthermore, none of the trials included in that previous review assessed clinically important outcomes. The present review included six trials with a total of 564 participants, and it provides higher certainty evidence for the favorable effects of CAI therapy on blood gases parameters. In addition, two trials included in our review assessed clinically important outcomes.

Although the results of the pooled analysis concerning mortality and duration of hospital stay are not conclusive, they suggest a possible decrease in the duration of mechanical ventilation in the CAI group compared with placebo. This clinically important outcome should be confirmed in future larger randomized clinical trials.

\section{Conclusion}

The present systematic review demonstrates that carbonic anhydrase inhibitors are associated with favorable blood gas parameters in patients with respiratory failure and metabolic alkalosis, but did not

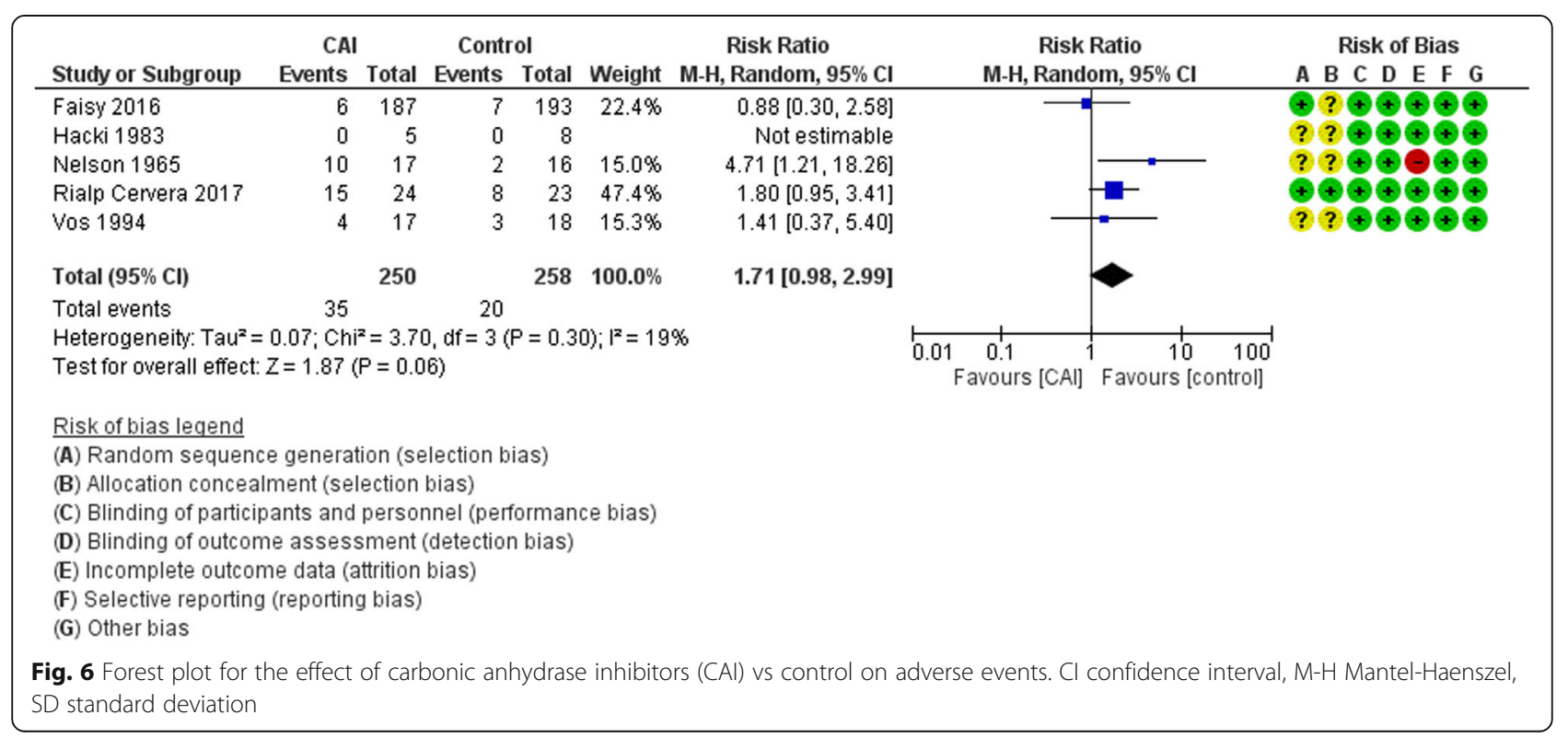


provide conclusive results for clinically important outcomes. Future well-designed and large randomized trials should investigate the effect of carbonic anhydrase inhibitors on these outcomes, particularly mortality, duration of hospital stay, and duration of mechanical ventilation.

\section{Additional files}

Additional file 1: Details of the methods. (PDF $41 \mathrm{~kb}$ )

Additional file 2: Table S1. MEDLINE search strategy. Table S2. EMBASE search strategy. Table S3. SCOPUS search strategy. Table S4 Cochrane CENTRAL search strategy. Table S5. Funding and conflict of interest of authors in the included trials. Figure S1. Risk of bias summary. Figure S2. Forest plot for the effect of CAI vs control on mortality. Figure S3. Forest plot for the effect of CAI vs control on duration of hospital stay. Figure S4. Forest plot for the effect of CAI vs control on duration of mechanical ventilation. Figure S5. Forest plot for the effect of CAl vs control on $\mathrm{PaCO}_{2}$ using standardized mean difference. Figure S6. Forest plot for the effect of CAl vs control on $\mathrm{PaO}_{2}$ using standardized mean difference. Figure S7. Forest plot for the effect of CAI vs control on serum bicarbonate using standardized mean difference. Figure S8. Forest plot for the effect of CAl vs control on $\mathrm{pH}$ using standardized mean difference. (PDF 338 kb)

\section{Abbreviations}

CAl: Carbonic anhydrase inhibitors; Cl: Confidence interval; COPD: Chronic obstructive pulmonary disease; IQR: Interquartile range; MD: Mean difference; MV: Mechanical ventilation; NIPPV: Noninvasive positive-pressure ventilation; RCT: Randomized controlled trial; RR: Risk ratio; SD: Standard deviation; SMD: Standardized mean difference; SoF: Summary of findings

\section{Acknowledgments}

We acknowledge the contribution of our university librarian Ms. Aida Farha in the design of the search strategy and providing full-text material for our systematic review. We also acknowledge Dr. Bouchra Tawk for her help in translating and abstracting data from the article in the German language, and Dr. Assem Khamis for his help with the statistical analysis.

\section{Funding}

The authors declare that they did not receive any funding for this work.

\section{Availability of data and materials}

The datasets used and/or analyzed in the current study are available from the corresponding author upon request.

\section{Authors' contributions}

BYT, HSI, CN, EAA, PKBK, and SSM designed the study. TL and MOO designed the search strategy and performed the search. BYT, HSI, CN, MOO, and TL performed abstract screening, full text screening, data extraction, and risk of bias assessment. BYT and MOO performed data analysis. SSM, PKBK, and EAA helped in finalizing the full text screening, and in data interpretation. EAA participated in the statistical analysis, risk of bias assessment, and the rating of the certainty of evidence. BYT drafted the manuscript. All authors revised the manuscript and read and approved the final manuscript.

\section{Ethics approval and consent to participate}

Not applicable.

\section{Consent for publication}

All authors have agreed to the publication of this manuscript.

\section{Competing interests}

The authors declare that they have no competing interests.

\section{Publisher's Note}

Springer Nature remains neutral with regard to jurisdictional claims in published maps and institutional affiliations.

\section{Author details}

${ }^{1}$ Division of Nephrology and Hypertension, American University of Beirut Medical Center, Beirut, Lebanon. ${ }^{2}$ Faculty of Health Sciences, American University of Beirut, Beirut, Lebanon. '3Division of pulmonary and critical care, Keserwan Medical Center, Ghazir, Lebanon. ${ }^{4}$ Clinical Research Institute, and Faculty of Health Sciences, American University of Beirut, Beirut, Lebanon. ${ }^{5}$ Division of Pulmonary and Critical Care, American University of Beirut Medical Center, Beirut, Lebanon. 'Department of Internal Medicine, American University of Beirut, Beirut, Lebanon. ${ }^{7}$ Division of Nephrology and Hypertension, Makassed General Hospital, Beirut, Lebanon. ${ }^{8}$ Department of Internal Medicine, American University of Beirut Medical Center, PO Box 11-0236, Riad El-Solh, Beirut 1107 2020, Lebanon.

Received: 20 July 2018 Accepted: 24 September 2018

Published online: 29 October 2018

\section{References}

1. Holland AE, Wilson JW, Kotsimbos TC, Naughton MT. Metabolic alkalosis contributes to acute hypercapnic respiratory failure in adult cystic fibrosis. Chest. 2003;124(2):490-3.

2. Hodgkin JE, Soeprono FF, Chan DM. Incidence of metabolic alkalemia in hospitalized patients. Crit Care Med. 1980;8(12):725-8.

3. Heming $N$, Urien S, Faisy C. Acetazolamide: a second wind for a respiratory stimulant in the intensive care unit? Critical care (London, England). 2012; 16(4):318.

4. Banga A, Khilnani GC. Post-hypercapnic alkalosis is associated with ventilator dependence and increased ICU stay. Copd. 2009;6(6):437-40.

5. Jones PW, Greenstone M. Carbonic anhydrase inhibitors for hypercapnic ventilatory failure in chronic obstructive pulmonary disease. Cochrane Database Syst Rev 2001(1):Cd002881. https://www.ncbi.nlm.nih.gov/ pubmed/11279770.

6. Faisy C, Meziani F, Planquette B, Clavel M, Gacouin A, Bornstain C, et al. Effect of acetazolamide vs placebo on duration of invasive mechanical ventilation among patients with chronic obstructive pulmonary disease: a randomized clinical trial. JAMA. 2016;315(5):480-8.

7. Fontana V, Santinelli S, Internullo M, Marinelli P, Sardo L, Alessandrini G, et al. Effect of acetazolamide on post-NIV metabolic alkalosis in acute exacerbated COPD patients. Eur Rev Med Pharmacol Sci. 2016;20(1):37-43.

8. Rialp Cervera G, Raurich Puigdevall JM, Moran Chorro I, Martin Delgado MC, Heras la Calle G, Mas Serra A, et al. Effects of early administration of acetazolamide on the duration of mechanical ventilation in patients with chronic obstructive pulmonary disease or obesity-hypoventilation syndrome with metabolic alkalosis. A randomized trial. Pulm Pharmacol Ther. 2017:44:30-7.

9. Liberati A, Altman DG, Tetzlaff J, Mulrow C, Gotzsche PC, loannidis JP, et al. The PRISMA statement for reporting systematic reviews and meta-analyses of studies that evaluate health care interventions: explanation and elaboration. PLoS Med. 2009;6(7):e1000100.

10. Higgins JPT GS. Cochrane handbook for systematic reviews of interventions Version 5.1.0 The Cochrane Collaboration, 2011; 2011 [updated updated March 2011]. Available from: Available from https://handbook-5-1.cochrane. org/. Accessed Aug 2017.

11. Higgins JP, Altman DG, Gotzsche PC, Juni P, Moher D, Oxman AD, et al. The Cochrane Collaboration's tool for assessing risk of bias in randomised trials. BMJ (Clinical research ed). 2011;d5928:343.

12. Nelson WM, Wallace WF. Oral respiratory stimulants in chronic respiratory failure: double-blind controlled trial of amiphenazole and dichlorphenamide. Br Med J. 1965;1(5437):759-62.

13. Furukawa TA, Barbui C, Cipriani A, Brambilla P, Watanabe N. Imputing missing standard deviations in meta-analyses can provide accurate results. J Clin Epidemiol. 2006;59(1):7-10.

14. Faisy C, Mokline A, Sanchez O, Tadie JM, Fagon JY. Effectiveness of acetazolamide for reversal of metabolic alkalosis in weaning COPD patients from mechanical ventilation. Intensive Care Med. 2010;36(5):859-63.

15. Hacki M, Waldeck G, Brandli O. Acetazolamide in hypercapnic chronic obstructive pulmonary disease: a renaissance? Schweizerische medizinische Wochenschrift [Internet]. 1983; 113(3):[110-4 pp.]. Available from: https:// www.cochranelibrary.com/central/doi/10.1002/central/CN-00175914/full. 
16. Rohatgi A. WebPlotDigitizer January, 2018. Version 4.1:[Available from: https://automeris.io/WebPlotDigitizer. Accessed Feb 2018

17. Wood L, Egger M, Gluud LL, Schulz KF, Juni P, Altman DG, et al. Empirical evidence of bias in treatment effect estimates in controlled trials with different interventions and outcomes: meta-epidemiological study. BMJ (Clinical research ed). 2008;336(7644):601-5.

18. Akl EA, Johnston BC, Alonso-Coello P, Neumann I, Ebrahim S, Briel M, et al. Addressing dichotomous data for participants excluded from trial analysis: a guide for systematic reviewers. PLoS One. 2013;8(2):e57132.

19. Ebrahim S, Akl EA, Mustafa RA, Sun X, Walter SD, Heels-Ansdell D, et al. Addressing continuous data for participants excluded from trial analysis: a guide for systematic reviewers. J Clin Epidemiol. 2013;66(9):1014-21 e1.

20. Ebrahim S, Johnston BC, Akl EA, Mustafa RA, Sun X, Walter SD, et al. Addressing continuous data measured with different instruments for participants excluded from trial analysis: a guide for systematic reviewers. J Clin Epidemiol. 2014;67(5):560-70.

21. Guyatt GH, Ebrahim S, Alonso-Coello P, Johnston BC, Mathioudakis AG, Briel $M$, et al. GRADE guidelines 17: assessing the risk of bias associated with missing participant outcome data in a body of evidence. J Clin Epidemiol. 2017:87:14-22

22. Guyatt G, Oxman AD, Akl EA, Kunz R, Vist G, Brozek J, et al. GRADE guidelines: 1. Introduction-GRADE evidence profiles and summary of findings tables. J Clin Epidemiol. 2011;64(4):383-94.

23. Guyatt GH, Oxman AD, Vist G, Kunz R, Brozek J, Alonso-Coello P, et al. GRADE guidelines: 4. Rating the quality of evidence - study limitations (risk of bias). J Clin Epidemiol. 2011;64(4):407-15.

24. Guyatt GH, Oxman AD, Kunz R, Woodcock J, Brozek J, Helfand M, et al. GRADE guidelines: 7. Rating the quality of evidence-inconsistency. J Clin Epidemiol. 2011;64(12):1294-302.

25. Guyatt GH, Oxman AD, Kunz R, Woodcock J, Brozek J, Helfand M, et al. GRADE guidelines: 8. Rating the quality of evidence-indirectness. J Clin Epidemiol. 2011;64(12):1303-10.

26. Guyatt GH, Oxman AD, Montori V, Vist G, Kunz R, Brozek J, et al. GRADE guidelines: 5. Rating the quality of evidence-publication bias. J Clin Epidemiol. 2011;64(12):1277-82.

27. GRADEpro GDT: GRADEpro Guideline Development Tool [Software]. McMaster University, 2015 (developed by Evidence Prime, Inc.). Available from gradepro.org. Accessed Apr 2018.

28. Gulsvik R, Skjorten I, Undhjem K, Holo L, Frostad A, Saure EW, et al. Acetazolamide improves oxygenation in patients with respiratory failure and metabolic alkalosis. Clin Respir J. 2013;7(4):390-6.

29. Vos PJ, Folgering HT, de Boo TM, Lemmens WJ, van Herwaarden CL. Effects of chlormadinone acetate, acetazolamide and oxygen on awake and asleep gas exchange in patients with chronic obstructive pulmonary disease (COPD). Eur Respir J. 1994;7(5):850-5.

30. Hacki MA, Waldeck G, Brandli O. Acetazolamide in hypercapnic chronic obstructive lung disease-a renaissance? Schweizerische Medizinische Wochenschrift. 1983;113(3):110-4.

31. Skatrud JB, Dempsey JA. Relative effectiveness of acetazolamide versus medroxyprogesterone acetate in correction of chronic carbon dioxide retention. Am Rev Respir Dis. 1983;127(4):405-12.

32. Wagenaar M, Vos $P$, Heijdra $Y$, Teppema $L$, Folgering $H$, Correspondence $A$, et al. Comparison of acetazolamide and medroxyprogesterone as respiratory stimulants in hypercapnic patients with COPD. Chest. 2003;123(5):1450-9.

\section{Ready to submit your research? Choose BMC and benefit from:}

- fast, convenient online submission

- thorough peer review by experienced researchers in your field

- rapid publication on acceptance

- support for research data, including large and complex data types

- gold Open Access which fosters wider collaboration and increased citations

- maximum visibility for your research: over $100 \mathrm{M}$ website views per year

At BMC, research is always in progress.

Learn more biomedcentral.com/submissions 